- Original Article

\title{
Healthy Beliefs regarding Breast Cancer Screening in Iranian Women Health Volunteers: A Path Analysis
}

\author{
Fatemeh Salmani', Mitra Moodi ${ }^{2}$, Azam Yousefi ${ }^{3}$, Ensiyeh Norozi ${ }^{2, *}$ \\ 'Social Determinants of Health Research Center, Department of Epidemiology and Biostatistics, Faculty of Health, Birjand University of Medical \\ Sciences, Birjand, Iran \\ ${ }^{2}$ Social Determinants of Health Research Center, Department of Public Health, Faculty of Health, Birjand University of Medical Sciences, Birjand, Iran \\ ${ }^{3}$ Social Determinants of Health Research Center, Student Research Committee, Birjand University of Medical Science, Birjand, Iran
}

Background: In Iran, $82 \%$ of breast cancer cases are diagnosed in late stages, resulting in low survival rates. In the present study, the Stages of Change Theory and Health Belief Model were used as theoretical frameworks for assessing Women Health Volunteer readiness to act on different breast cancer screening behaviors.

Methods: A total of 1,410 Women Health Volunteers were enrolled in this cross-sectional study. The breast self-examination (BSE) and mammography stages of change were measured independently. A standardized questionnaire based on the Health Belief Model was used to assess their beliefs about breast cancer screening methods. A path analysis using PASW SPSS ver. 18.0 (SPSS Inc., Chicago, IL, USA) was used to test the effects of individual beliefs on breast cancer screening stages of change.

Results: Most participants were classified in the pre-contemplation stage of breast cancer screening behaviors. Perceived barriers, benefits, and susceptibility emerged as BSE stages of change predictors. No beliefs were significant mammography stages of change predictors.

Conclusion: Iranian Women Health Volunteers had a very low adherence to common BSE and mammography practices. Healthy beliefs have a strong association with the stages of change for performing BSE, but not for mammography. The impact of health beliefs on an individual's readiness to act on different breast cancer screening methods may vary with respect to the type of screening method.

Keywords: Breast Neoplasms; Early Detection of Cancer; Breast; Self-Examination; Mammography; Attitude

Received: January 1, 2020, Revised: March 9, 2020, Accepted: March 17, 2020

${ }^{*}$ Corresponding Author: Ensiyeh Norozi https://orcid.org/0000-0002-6898-0493

Tel: +98-056-32381653, Fax: +98-056-31631651, E-mail: ensiyehnorozi@bums.ac.ir 


\section{INTRODUCTION}

Breast cancer is the leading cause of cancer deaths in women in developing countries, and it is the second leading cause in developed countries. ${ }^{1)}$ It is estimated that over 508,000 women died from this disease worldwide in 2011 . Nearly $50 \%$ of breast cancer cases and $58 \%$ of deaths occur in under-developed countries. ${ }^{2)}$ In Iran, breast cancer has been identified as the most common malignancy in females, comprising $24.4 \%$ of all cancers with an age-standardized rate of 23.1 per $100,000 .{ }^{3)}$ Five-year breast cancer survival rates differ greatly in different settings, ranging from $80 \%$ or more in settings where early detection and basic treatment are available and accessible and $10 \%-40 \%$ in resource-poor settings. ${ }^{4,5)}$ Lack of early detection programs, diagnosis delays, and lack of treatment facilities are the main causes of low survival rates in under-developed countries, resulting in a high proportion of women presenting with late-stage disease. ${ }^{2)}$ In Iran, the results of an epidemiological review on breast cancer showed that most breast cancer cases (82\%) are diagnosed in late stages. Also, a high proportion of breast cancer patients in Iran present at least 10 years younger than their Western counterparts. ${ }^{6}$ )

Given the nature of breast cancer, early detection is the most important measure to improve survival rates. ${ }^{4)}$ Breast cancer screening methods include breast self-examination (BSE), clinical breast examination (CBE) and mammography. Based on the American Cancer Society screening recommendations for women with an average breast cancer risk, regular mammograms are the only method that have proven to be effective in finding breast cancer at an early stage when treatment is most successful; however, research has not shown a clear benefit of regular BSE and CBE. ${ }^{7)}$ Although there is controversy surrounding the efficacy of BSE, this method remains a cost-effective method to detect breast cancer in developing countries with weak healthcare systems. ${ }^{8,9)}$ Unfortunately, studies conducted among different groups of Iranian women showed that adherence rates to recommended breast cancer screening guidelines in Iran are low. ${ }^{10-17)}$ Results of a systematic review on attitudes and practices regarding early detection of breast cancer among Iranian Women showed only an average of $21.9 \%, 15.8 \%$, and $16.7 \%$ of Iranian women perform BSE, CBE, and mammography, respectively. ${ }^{10)}$

The most important factors affecting the low participation in different breast cancer screening methods included lack of perceived self efficacy, lack of motivation for health, and different perceived barriers including belief that the practices were time-consuming, embarrassment, fear of pain, and lack of knowledge on the importance of breast cancer screening and how to do it. ${ }^{11,12,18-20)}$

The Women Health Volunteer (WHV) program is an important part of Iranian health services delivery. WHVs are interested local women who are trained to conduct regular home visits to disseminate health messages within their communities. ${ }^{21)}$ WHVs could play a vital role in increasing screening awareness and reducing screening barriers by dispelling screening misconceptions and providing comprehensive education to keep women engaged in their health. Unfortunately, re- search studying the status of breast cancer screening behaviors and related factors is limited. Therefore, the purpose of this study was to identify the status of breast cancer screening behaviors among Iranian WHVs. For this reason, the Stages of Change Theory (SCT) ${ }^{22)}$ and Health Belief Model (HBM ${ }^{23)}$ were used as theoretical frameworks for assessing WHV readiness to act on different breast cancer screening behaviors. SCT states that individuals adopting a new behavior move through six stages of change including: pre-contemplation, contemplation, preparation, action, maintenance, and relapse. ${ }^{22)}$ On the other hand, HBM suggests that a person's beliefs about health problems including perceived susceptibility and severity combined with the perceived benefits of action and barriers to action and self-efficacy explain engagement in health-promoting behaviors. ${ }^{23)}$

\section{METHODS}

\section{Participants}

This cross-sectional study was conducted with a sample of WHVs recruited from 11 cities of the Southern Khorasan Province from June to November 2016. Multi-stage cluster sampling was used to select the participants. The cities served as the cluster and the number women selected from each city were proportional to the WHV population in each cluster. Subjects were included if they were between 20 and 65 years of age with no personal history of breast cancer. Women who were pregnant or breast feeding at the time of recruitment were excluded. Not completing the questionnaire was also considered exclusion criteria. Of the 1,627 eligible subjects recruited, 1,410 (86.66\%) consented to participate. The most common reason for refusal included participant lack of interest in the study.

\section{Measures}

All measures were self-administered and required a 10-minute completion time. The following points provide a description of each measure.

Socio demographic characteristics consisted of age (in years), marriage age, age at first pregnancy, number of children, marital status, educational level, employment status, breastfeeding duration, menopausal status, insurance type, first-degree relatives with a history of breast cancer, personal history of breast problems, and qualitative assessment of income.

The mammography stage of change was measured by a single item that assessed the mammography behavior stages of change. This item was adapted from a study by Rakowski et al. ${ }^{24)}$ where each participant response was classified into one of the five stages: (1) pre-contemplation (never had a mammogram; not planning to get one in the coming year), (2) contemplation (never had a mammogram; considering having one in the coming year), (3) action (had a mammogram at agespecific interval; intend to have another one in the coming year), (4) maintenance (had at least two scheduled mammograms; intend to get another one in the coming year), and (5) relapse (had one or more past mammograms; no intention of having another one). 
The BSE stage of change was measured by a single assessment item that was adapted from Prochaska's stage of change definition ${ }^{22)}$ where each participant response was classified into one of the six stages: (1) pre-contemplation (never performed a BSE; not contemplating performing one in the next 6 months), (2) contemplation (never performed a BSE; contemplating performing one in the next 6 months), (3) preparation (never performed a BSE; contemplating performing one in the next month), (4) action (performed regular BSE in the past 6 months; intends to continue), (5) maintenance (performed regularly scheduled BSE; intends to continue), and (6) relapse (performed regular BSE in the past; no intention of continuing). Single item content validity was assessed by a panel of experts including four health educators, four gynecologists, and two society health nurses. Item clarity was also assessed by 20 women similar to the study target group.

Participant health beliefs and perceptions about breast cancer and breast cancer screening methods were measured with a 46-item questionnaire based on the HBM: perceived susceptibility to breast cancer (three items), perceived breast cancer severity (five items), perceived BSE benefits (five items), perceived mammography benefits (five items), perceived BSE barriers (eight items), perceived mammography barriers (eight items), perceived BSE self-efficacy (eight items), and perceived mammography self-efficacy (four items). Participants were asked to rate their beliefs for each item on a 5-point Likert scale (ranging from $1=$ strongly disagree to $5=$ strongly agree). These items were adapted from the Champion Health Belief Model Scale. ${ }^{25)}$ Content validity ratio and content validity index were used to ensure questionnaire content validity. Content validity was determined by a panel of experts (four health educators, four gynecologists, and two society health nurses). A test of internal consistency was used to ensure the reliability of each questionnaire subscale. Cronbach's $\alpha$ was adequate for the overall scale and each questionnaire subscale $(\alpha \geq 0.70)$.

Individual knowledge about breast cancer screening methods was measured with five items. Each correct response was scored 1 point and each wrong response scored 0 point. Item content validity was assessed by a panel of experts (four health educators, four gynecologists, and two society health nurses). Pre-testing was performed on 20 women to ensure the clarity of each item.

\section{Data Analysis}

PASW SPSS ver. 18.0 (SPSS Inc., Chicago, IL, USA) and LISREL ver. 8.8 (Scientific Software International, Lincolnwood, IL, USA) were used to analyze the data. Summary statistics (means, standard deviation, frequencies, and percent) were used to describe participant characteristics and stages of change for breast cancer screening behaviors. A path analysis was used to identify the effects of each belief on breast cancer screening stages of change. The path analysis is a statistical method used to evaluate causal models by testing direct and indirect relationships between a response and two or more covariates. It is a form of multiple regressions that examines relations in a path graph ${ }^{26)}$ Therefore, the path analysis provides a great deal of information on casual processes in a simple way. ${ }^{27)}$ The assumed models were designed based on the HBM conceptual model. ${ }^{28)}$ P-values less than 0.05 were statistically significant. All tests were done after data normality was verified with the one sample Kolmogorov-Smirnov test.

\section{Ethics Approval and Consent to Participate}

All the procedures were approved by the Medical Sciences Ethics Committee (Ir.bums. 2016.35). The study was described to the participants and they were assured that their participation was voluntary. Written informed consent was provided by all the participants.

\section{RESULTS}

Of the 1,410 distributed questionnaires, 1,387 of the questionnaires were completed. Among them, 428 participants were 40 years of age and older. The incomplete questionnaires were excluded from the analysis. Study participant ages ranged from 20 to 65 years with a mean of $36.16 \pm 8.81$ years. The largest proportion of women was married $(93.2 \%)$ and unemployed (87.6\%). The mean age at first pregnancy was $21.83 \pm 3.70$ years, the mean age at marriage was $20.33 \pm 3.74$ years, and the number of children was $2.59 \pm 1.28$. Only $13.4 \%$ completed college. Most of the women (99.3\%) had health insurance. A small number of women $(2.6 \%)$ had first-degree relatives with a history of

Table 1. Participant demographic characteristics $(n=1,387)$

\begin{tabular}{|c|c|c|}
\hline Characteristic & $\begin{array}{l}\text { Mammography } \\
\quad(n=428)\end{array}$ & $\begin{array}{l}\text { Self-examination } \\
\qquad(n=1,387)\end{array}$ \\
\hline Age (y) & $46.44 \pm 5.37$ & $36.16 \pm 8.81$ \\
\hline \multicolumn{3}{|l|}{ Marital status } \\
\hline Married & $415(96.7)$ & 1,292 (93.2) \\
\hline Divorced or separated & $9(2.1)$ & $42(3)$ \\
\hline Single & $5(1.2)$ & $53(3.8)$ \\
\hline \multicolumn{3}{|l|}{ Educational level } \\
\hline <Diploma & $322(73.50)$ & $783(56.5)$ \\
\hline Diploma & $95(21.70)$ & $418(30.1)$ \\
\hline Attended college & $21(4.80)$ & $186(13.4)$ \\
\hline \multicolumn{3}{|l|}{ Occupation status } \\
\hline Housekeeper & $379(87.9)$ & $1,215(87.6)$ \\
\hline Employed part-time & $16(3.7)$ & $50(3.6)$ \\
\hline Employed full-time & $36(8.4)$ & $122(8.8)$ \\
\hline \multicolumn{3}{|l|}{ Economic situation } \\
\hline Poor & $92(21.7)$ & $351(25.3)$ \\
\hline Moderate & $290(68.6)$ & $909(65.6)$ \\
\hline Good & $41(9.7)$ & $127(9.2)$ \\
\hline \multicolumn{3}{|l|}{ Health insurance } \\
\hline Yes & 431 (99.5) & $1,381(99.4)$ \\
\hline No & $2(0.5)$ & $9(0.6)$ \\
\hline \multicolumn{3}{|c|}{$\begin{array}{l}\text { History of breast cancer in first } \\
\text { degree relatives }\end{array}$} \\
\hline Yes & $21(4.9)$ & $36(2.6)$ \\
\hline No & $409(95.1)$ & $1,351(97.4)$ \\
\hline \multicolumn{3}{|l|}{$\begin{array}{l}\text { History of education about } \\
\text { cervical cancer }\end{array}$} \\
\hline Yes & $368(86.1)$ & $1,111(80.1)$ \\
\hline No & $58(13.9)$ & $276(19.9)$ \\
\hline
\end{tabular}

Values are presented as mean \pm standard deviation or number (\%). 
breast cancer. Most participants (65.5\%) evaluated their economic situation as moderate. The socio-demographic characteristics of the sample are presented in Table 1.

The frequency distribution of the BSE stages of adaptation is shown in Figure 1. Most participants were classified in the pre-contemplation stage, followed by the contemplation, action, maintenance, preparation, and relapse stages. The frequency distribution of the mammography behavior stages of adaptation are shown in Figure 2. Among the participants aged 40 and older $(n=428)$, the majority were classified in the pre-contemplation stage, followed by the contemplation, action, maintenance, and relapse stages.

The path analysis was used to identify the direct and indirect effects of the independent variables on breast cancer screening behaviors (BSE and mammography) in separate models. As shown in Figure 3, the perceived barriers, benefits, and susceptibility have significant effects on the BSE stages of change. Perceived severity and self-efficacy had no significant effects on the BSE stages of change. Given the beta

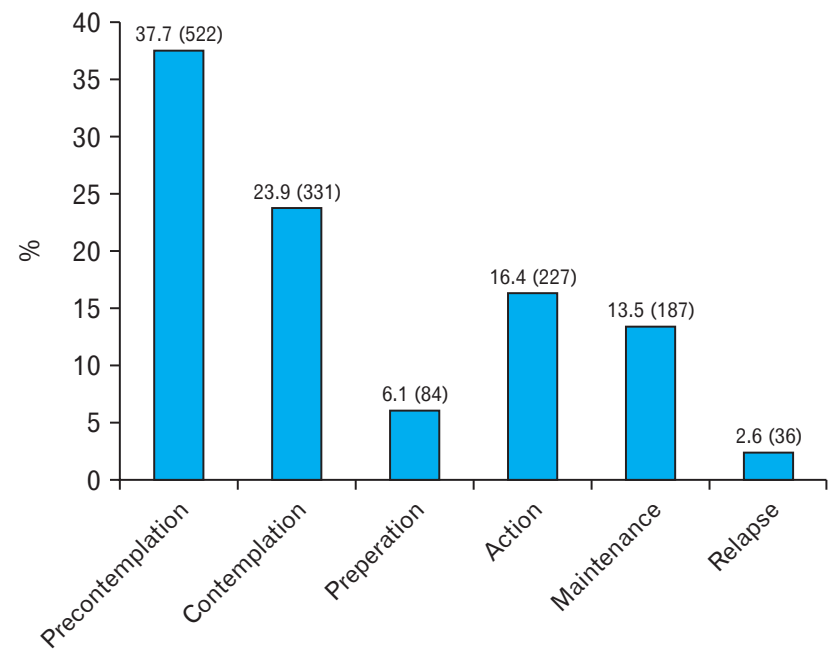

Stages of adaption for breast self examination behavior

Figure 1. Frequency distribution of stages of adaptation for breast self-examination behavior changes among Iranian Women Health Volunteers. Values are presented as $\%$ (number). coefficient for the total effect, perceived barriers have the greatest impact on the BSE stages of change and age and knowledge have indirect, significant effects. As shown in Table 2 and Figure 4, none of the HBM constructs have significant effects on the mammography stages of change.

\section{DISCUSSION}

In Iran, there is no national breast cancer screening program. On the other hand, breast cancer mortality is increasing in Iran. Therefore, Iranian women should be increasingly aware of the risk factors and signs of breast cancer as well as the availability of screening programs for an early diagnosis. ${ }^{3)}$ WHVs are an important group of people who can act as a bridge between healthcare services and their communities. ${ }^{21)}$ An understanding of the status of breast cancer screening behaviors and its identifying factors among this group is a pre-requisite to developing effective educational interventions to improve adher-

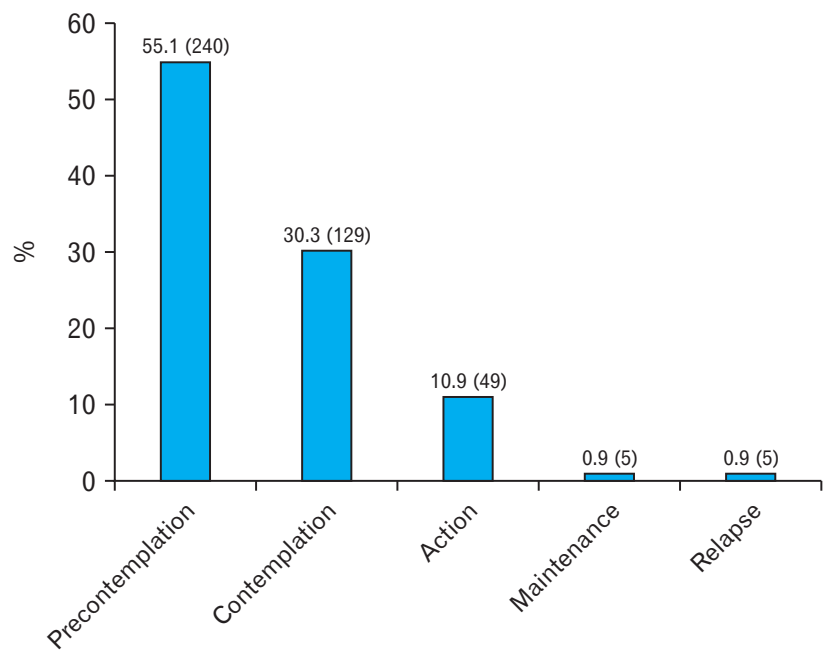

Stages of adaption for mammography behavior

Figure 2. Frequency distribution of stages of adaptation for mammography behavior changes among Iranian Women Health Volunteers. Values are presented as \% (number).

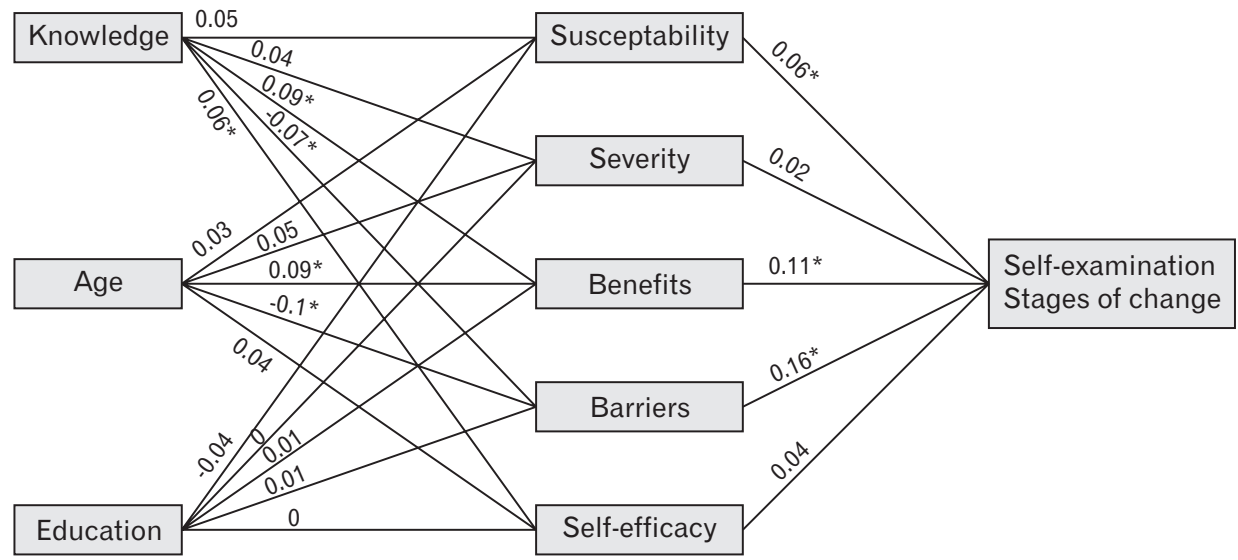

Figure 3. Cognitive predictors of breast selfexamination stages of change. Knowledge means the individual's knowledge about breast cancer screening methods. Education means the individual's education level. *Effect is significant at the 0.05 level (two-tailed) based on the path analysis method. 
Table 2. Standardized direct effect, indirect effect, and total effect of independent variables on breast self-examination and mammography

\begin{tabular}{|c|c|c|c|c|}
\hline Variable & Direct effect & Indirect effect & Total effect & $\mathrm{P}$-value \\
\hline \multicolumn{5}{|l|}{ Self-examination } \\
\hline Knowledge & - & 0.0049 & 0.0049 & 0.12 \\
\hline Age & - & -0.0017 & -0.0017 & 0.09 \\
\hline Education & - & 0.0003 & 0.0003 & 0.24 \\
\hline Perceived susceptibility & $0.06^{*}$ & - & $0.06^{\star}$ & $<0.001$ \\
\hline Perceived severity & 0.02 & - & 0.02 & 0.15 \\
\hline Perceived benefits & $0.11^{*}$ & - & $0.11^{*}$ & $<0.001$ \\
\hline Perceived barriers & $0.16^{*}$ & - & $0.16^{\star}$ & $<0.001$ \\
\hline Perceived self-efficacy & 0.04 & - & 0.04 & 0.19 \\
\hline \multicolumn{5}{|l|}{ Mammography } \\
\hline Knowledge & - & 0.0084 & 0.0084 & 0.16 \\
\hline Age & - & 0.0092 & 0.0092 & 0.11 \\
\hline Education & - & -0.0026 & -0.0026 & 0.31 \\
\hline Perceived susceptibility & 0.05 & - & 0.05 & 0.08 \\
\hline Perceived severity & -0.05 & - & -0.05 & 0.17 \\
\hline Perceived benefits & 0.02 & - & 0.02 & 0.75 \\
\hline Perceived barriers & -0.08 & - & -0.08 & 0.45 \\
\hline Perceived self-efficacy & 0.01 & - & 0.01 & 0.32 \\
\hline
\end{tabular}

${ }^{*}$ Effect is significant at the 0.05 level (two-tailed) based on path analysis method.

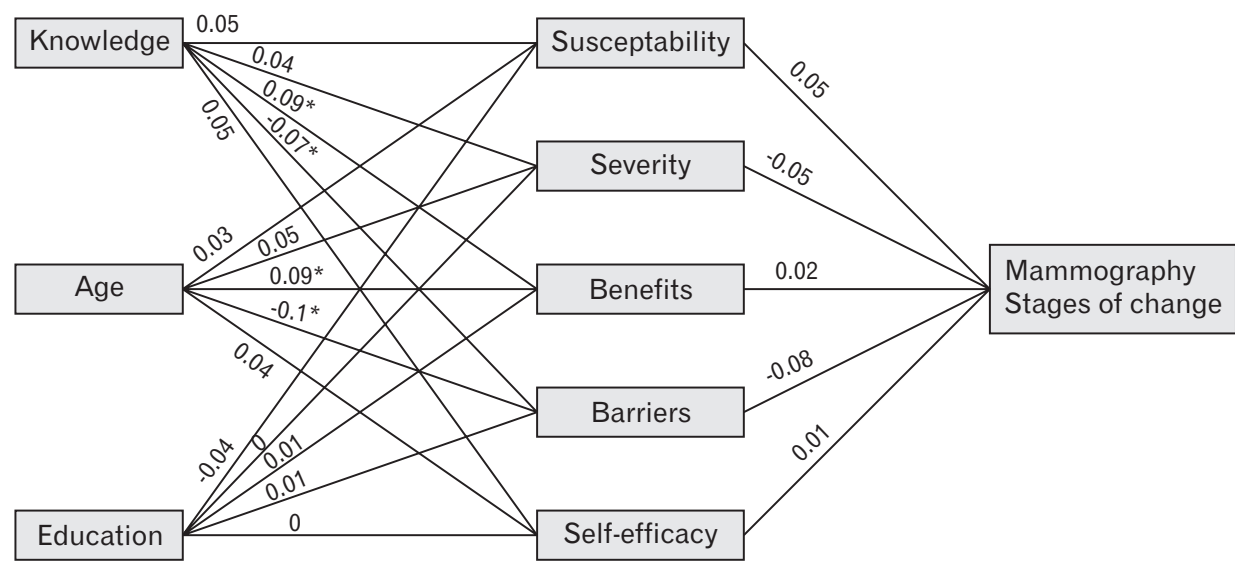

Figure 4. Cognitive predictors of mammography stages of change. Knowledge means the individual's knowledge about breast cancer screening methods. Education means the individual's education level. *Effect is significant at the 0.05 level (two-tailed) based on the path analysis method. ence to breast cancer screening activities in Iranian WHVs. In the present study, the SCT and HBM were used as theoretical frameworks for assessing WHV readiness to change their breast cancer screening behaviors.

As mentioned in the results section, most respondents (37.7\%) reported that they never performed a BSE and were not considering performing one in the next 6 months (pre-contemplation stage). Regular BSE (maintenance stage) was reported by only $13.5 \%$. A very low number of women performed regular BSE and intend to continue. Results of other studies in line with ours suggest that the rate of regular BSE performed by Iranian women is low. ${ }^{10,11,14)}$ For example, the results of a review indicate that the proportion of Iranian women who perform BSE ranges from $3 \%$ to $17 \%$, with the actual rate most likely on the lower end. ${ }^{12)}$ Regular BSE rates were also low in other developing countries. ${ }^{9,29)}$ Although the debate about the potential benefits of regular breast exams continues and research has not shown a clear benefit of regular BSE, ${ }^{7)}$ it is important to consider its role in screening women who do not have mammographic screening available. This is especially true for developing nations where BSE is a simple, inexpensive, and non-invasive method. ${ }^{9)}$ BSE can help women become familiar with how their breasts normally look and to report any changes to a health care provider, resulting in early detection and a better prognosis. More importantly, BSE can encourage women to take an active responsibility in preventive health.

Concerning mammography behaviors, most (55.1\%) reported that they never had a mammogram and were not planning to get one in the coming year (pre-contemplation stage) and regular mammography was reported by only $0.9 \%$ of WHV (maintenance stage). Regular mammography rates were also low in other studies among Iranian women. ${ }^{11,13-15,17)}$ For example, the regular mammography behavior rate among women in Isfahan was only $6.2 \%$ (maintenance stage) ${ }^{15)} \mathrm{Re}$ sults of other studies in line with ours suggest that the rate of regular mammography was also low in other developing countries. ${ }^{30)}$

Unfortunately, most of the WHVs were in the pre-contemplation 
stage of breast cancer screening behaviors. A very low number of women performed regular BSE or had a mammogram and intended to continue. Several potential factors may explain the low adherence to regular breast cancer screening behaviors among our study sample. Based on SCT assumptions, people may be in the pre-contemplation stage because they do not understand the consequences of their unhealthy behaviors or they may not have confidence in their abilities to perform healthy behaviors. ${ }^{22)}$ On the other hand, HBM acknowledges that an individual belief in a disease, such as perceived susceptibility and severity combined with a belief in recommended preventive behavior effectiveness, serve as individual behavior predictors. ${ }^{23)}$ According to our results, perceived barriers, benefits, and susceptibility emerged as BSE stages of change predictors among Iranian WHVs, while none of the HBM constructs had significant effects on the mammography stages of change. According to the BSE adaptation stages, women in later stages (for example, maintenance) demonstrated lower levels of perceived barriers, higher levels of perceived benefits, and higher levels of perceived susceptibility than women in the earlier stages (for example, pre-contemplation). Numerous studies have also shown that perceived barriers, benefits, and susceptibility are BSE predictors. ${ }^{11,18)}$ In our study, perceived barriers were the best BSE predictors. Perceived barriers refer to beliefs about the tangible and psychological costs of the recommended healthy behaviors. ${ }^{23)}$ The most important barriers to Iranian women not performing monthly BSE included being time-consuming, feeling embarrassed, and lack of knowledge of how to perform BSE. ${ }^{11,18)}$ Identifying and reducing perceived barriers through reassurance, correction of misinformation, incentives, and assistance could provide an opportunity to improve knowledge on how to perform monthly BSE and address any misconceptions about the BSE procedure. ${ }^{23)}$ Perceived benefits were the second most important predictor of regular BSE among WHVs. Perceived benefits refer to beliefs in the efficacy of the recommended healthy behaviors to reduce risk or disease threat. Based on HBM assumptions, individuals exhibiting optimal beliefs in susceptibility and severity are not expected to accept any recommended health action unless they also perceive the action as beneficial by reducing the threat. ${ }^{23)}$ Another regular BSE predictor was perceived susceptibility. Perceived susceptibility refers to beliefs about the likelihood of experiencing a risk of contracting a disease. ${ }^{23)}$ This finding is in line with our hypothesis. Based on HBM assumptions, women will be more likely to adhere to regular BSE if they feel susceptible to breast cancer.

As mentioned above, none of the HBM constructs had significant effects on the mammography stages of change. This finding is not in line with our hypothesis. Based on HBM assumptions, women will be more likely to adhere to mammography recommendations if they feel susceptible to breast cancer, believe that breast cancer is a severe disease, perceive barriers to screening lower than the perceived benefits, and have a higher self-efficacy for obtaining mammograms. ${ }^{28)}$ Many studies have confirmed these relationships between HBM constructs and mammography adherence. ${ }^{15,19,20)}$ Based on the results of some studies, perceived barriers and perceived benefits were the most im- portant HBM constructs that have a relationship with mammography adherence. Women who received regular mammograms perceived more benefits from the examination and fewer barriers to regular examination. ${ }^{19)}$ This inconsistent finding could be explained by several factors. In the current study, only the impact of cognitive factors on the mammography stages of change was investigated and the roles of other potential individualistic, social, and environmental factors that motivate women to adhere to mammography recommendations were not addressed. For example, there is only one mammography machine in the entire South Khorasan province and women had limited accessibility to it. Furthermore, a small percentage of participants in some of the mammography stages of change can have an effect on estimated pathway coefficients.

Unfortunately, there is no comprehensive national breast cancer screening program in Iran and women require a physician referral to receive mammography. On the other hand, insurance only pays a small part of the costs and patients must pay for mammography themselves. Therefore, providing low-cost or free access to mammograms, especially for women in low socioeconomic conditions, is essential. Also, the results of one study showed that a recommendation from a healthcare professional is a powerful factor related to Iranian women obtaining mammograms. ${ }^{20)}$ Thus, it seems that physicians, nurses, and other health care providers can play an important role in motivating and educating young women on the importance of adhering to breast cancer screening behaviors.

In the absence of a national breast cancer screening program in Iran, WHVs could play a vital role in promoting Iranian breast cancer screening behaviors and keep women engaged in their health. Even when WHVs are not directly involved in referring patients to breast cancer screening, they play an important role in creating an environment supportive of screening behaviors by being positive role models. However, the findings of this study showed that the status of breast cancer screening WHVs was not satisfactory and most participants were in the pre-contemplation stage. For these women, messages, strategies, and programs tailored to their needs might increase the odds of them changing and progressing to the next stage. Increased awareness of the need for change, and personalized information about the risks and benefits are essential to move individuals out of the precontemplation stage and into the contemplation stage. On the other hand, solely relying on education is not sufficient to promote healthy behaviors and it is essential to pay attention to the barriers and eliminate them. A national campaign, culturally sensitive health promotion efforts, and improved access to low-cost screening sites should be started to increase breast cancer screening behaviors. Also, the media, especially television, can be used to educate women on the importance of breast cancer screening behaviors, as well as motivate them to adhere to these behaviors. ${ }^{9)}$

This study has several limitations. First, this study sample was composed solely of female health volunteers in the Southern Khorasan province. Therefore, the results of this study should be applied with caution since they were based on a regional sample. Further research 
should be conducted on participants from different WHV socio-cultural backgrounds. Second, the possibility of participant over- or under-reporting should be considered. On the other hand, we only studied the impact of cognitive factors on breast cancer screening behaviors. Other possible individual, social, and environmental factors that motivate women to adhere to breast cancer screening behaviors were not addressed in this study. This suggests the importance of further study on the motivating factors for Iranian WHVs to adhere to breast cancer screening behaviors.

\section{CONFLICT OF INTEREST}

No potential conflict of interest relevant to this article was reported.

\section{ACKNOWLEDGMENTS}

The authors want to thank the WHVs involved in this study for participating and co-operating anonymously. Without them, this research would not have been possible.

\section{ORCID}

Fatemeh Salmani: https://orcid.org/0000-0001-6781-3899

Mitra Moodi: https://orcid.org/0000-0002-8877-6609

Azam Yousefi: https://orcid.org/0000-0002-5888-5089

Ensiyeh Norozi: https://orcid.org/0000-0002-6898-0493

\section{REFERENCES}

1. Seely JM, Alhassan T. Screening for breast cancer in 2018: what should we be doing today? Curr Oncol 2018;25(Suppl 1):S115-24.

2. World Health Organization. Breast cancer: prevention and control [Internet]. Geneva: World Health Organization; 2018 [cited 2018 Oct 27]. Available from: https://www.who.int/cancer/detection/breastcancer/ en/indexl.html.

3. Farhood B, Geraily G, Alizadeh A. Incidence and mortality of various cancers in Iran and compare to other countries: a review article. Iran J Public Health 2018;47:309-16.

4. Coleman MP, Quaresma M, Berrino F, Lutz JM, De Angelis R, Capocaccia R, et al. Cancer survival in five continents: a worldwide population-based study (CONCORD). Lancet Oncol 2008;9:730-56.

5. World Health Organization. WHO position paper on mammography screening 2018 [Internet]. Geneva: World Health Organization; 2018 [cited 2018 Nov 3]. Available from: http://www.who.int/cancer/publications/mammography_screening/en/.

6. Mousavi SM, Montazeri A, Mohagheghi MA, Jarrahi AM, Harirchi I, Najafi M, et al. Breast cancer in Iran: an epidemiological review. Breast J 2007;13:383-91.

7. American Cancer Society. American Cancer Society recommendations for the early detection of breast cancer [Internet]. Atlanta (GA): American Cancer Society; 2018 [cited 2018 Nov 3]. Available from: https://www.cancer.org/cancer/breast-cancer/screening-tests-andearly-detection/american-cancer-society-recommendations-for-the- early-detection-of-breast-cancer.html.

8. Brennan ME. The role of clinical breast examination in cancer screening for women at average risk: a mini review. Maturitas 2016;92:61-3.

9. Nde FP, Assob JC, Kwenti TE, Njunda AL, Tainenbe TR. Knowledge, attitude and practice of breast self-examination among female undergraduate students in the University of Buea. BMC Res Notes 2015;8:43.

10. Badakhsh M, Balouchi A, Taheri S, Bouya S, Ahmadidarehsima S, Aminifard M. Attitude and practice regarding breast cancer early detection among Iranian women: a systematic review. Asian Pac J Cancer Prev 2018;19:9-16.

11. Fouladi N, Pourfarzi F, Mazaheri E, Asl HA, Rezaie M, Amani F, et al. Beliefs and behaviors of breast cancer screening in women referring to health care centers in northwest Iran according to the Champion Health Belief Model Scale. Asian Pac J Cancer Prev 2013;14:6857-62.

12. Babu GR, Samari G, Cohen SP, Mahapatra T, Wahbe RM, Mermash S, et al. Breast cancer screening among females in Iran and recommendations for improved practice: a review. Asian Pac J Cancer Prev 2011; 12:1647-55.

13. Moghaddam Tabrizi F, Vahdati S, Khanahmadi S, Barjasteh S. Determinants of breast cancer screening by mammography in women referred to health centers of Urmia, Iran. Asian Pac J Cancer Prev 2018; 19:997-1003.

14. Hajian-Tilaki K, Auladi S. Health Belief Model and practice of breast self-examination and breast cancer screening in Iranian women. Breast Cancer 2014;21:429-34.

15. Moodi M, Rezaeian M, Mostafavi F, Sharifirad GR. Mammography stage of adoption among Iranian women. J Educ Health Promot 2012; 1:37.

16. Mirzaei-Alavijeh M, Ghorbani P, Jalilian F. Socio-cognitive determinants of the mammography screening uptake among Iranian women. Asian Pac J Cancer Prev 2018;19:1351-5.

17. Shiryazdi SM, Kholasehzadeh G, Neamatzadeh H, Kargar S. Health beliefs and breast cancer screening behaviors among Iranian female health workers. Asian Pac J Cancer Prev 2014;15:9817-22.

18. Tavafian SS, Hasani L, Aghamolaei T, Zare S, Gregory D. Prediction of breast self-examination in a sample of Iranian women: an application of the Health Belief Model. BMC Womens Health 2009;9:37.

19. Moodi M, Rezaeian M, Mostafavi F, Sharifirad GR. Determinants of mammography screening behavior in Iranian women: a populationbased study. J Res Med Sci 2012;17:750-9.

20. Allahverdipour H, Asghari-Jafarabadi M, Emami A. Breast cancer risk perception, benefits of and barriers to mammography adherence among a group of Iranian women. Women Health 2011;51:204-19.

21. Alami A, Nedjat S, Majdzadeh R, Rahimi Foroushani A, Hoseini SJ, et al. Factors influencing women's willingness to volunteer in the healthcare system: evidence from the Islamic Republic of Iran. East Mediterr Health J 2013;19:348-55.

22. Prochaska JO, Redding CA, Evers KE. The transtheoretical model and stages of change. In: Glanz K, Rimer BK, Lewis FM, editors. Health behavior and health education: theory, research, and practice. 3rd ed. San Francisco (CA): Jossey-Bass; 2002. p. 99-120.

23. Rosenstock IM, Strecher VJ, Becker MH. Social learning theory and the Health Belief Model. Health Educ Q 1988;15:175-83.

24. Rakowski W, Ehrich B, Dube CE, Pearlman DN, Goldstein MG, Peterson $\mathrm{KK}$, et al. Screening mammography and constructs from the 
transtheoretical model: associations using two definitions of the stages-of-adoption. Ann Behav Med 1996;18:91-100.

25. Champion VL, Scott CR. Reliability and validity of breast cancer screening belief scales in African American women. Nurs Res 1997;46: 331-7.

26. Glozah FN, Pevalin DJ. Social support, stress, health, and academic success in Ghanaian adolescents: a path analysis. J Adolesc 2014;37: 451-60.

27. Alwin DF, Hauser RM. The decomposition of effects in path analysis. Am Sociol Rev 1975;40:37-47.
28. Glanz K, Rimer BK, Viswanath K. Health behavior and health education: theory, research, and practice. 4 th ed. San Francisco (CA): JosseyBass; 2008.

29. Grosse Frie K, Ramadas K, Anju GA, Mathew BS, Muwonge R, Sauvaget CS, et al. Determinants of participation in a breast cancer screening trial in trivandrum district, India. Asian Pac J Cancer Prev 2013;14: 7301-7.

30. Akhigbe AO, Omuemu VO. Knowledge, attitudes and practice of breast cancer screening among female health workers in a Nigerian urban city. BMC Cancer 2009;9:203. 